\title{
КОНСТИТУЦИОННО-ПРАВОВЫЕ ОСНОВЫ ГОСУДАРСТВЕННОЙ СЛУЖБЫ В РОССИЙСКОЙ ФЕДЕРАЦИИ И КИТАЙСКОЙ НАРОДНОЙ РЕСПУБЛИКЕ: СРАВНИТЕЛЬНО-ПРАВОВОЙ АНАЛИЗ
}

\section{CONSTITUTIONAL AND LEGAL FOUNDATIONS OF PUBLIC SERVICE IN THE RUSSIAN FEDERATION AND THE PEOPLE'S REPUBLIC OF CHINA: A COMPARATIVE LEGAL ANALYSIS}

A. Novikov

E. Delegeoz

Summary. The subject of the article is a set of norms of Chinese and Russian legislation concerning the legal regulation of relations in the sphere of the state civil service. The article analyzes the provisions of Chinese legislation concerning admission to the state civil service, training of state civil servants and the prevention of corruption among officials.

As a result of the analysis, the author comes to the conclusion that China and Russia are using a wide range of legal liability measures in order to counteract corruption offenses. In China, a system of "double rails" is used - an approach in which the responsibility of persons suspected of corruption crimes comes first through the party line and then through the law enforcement agencies. In Russia, serious additions were made to disciplinary measures in terms of introducing a new type of punishment - dismissal due to loss of confidence, which can be applied in cases of non-compliance with anti-corruption restrictions and prohibitions.

On the basis of the comparative legal analysis, a conclusion is made about the mutual improvement of the legislation of China and Russia by introducing the best theoretical provisions and practical experience into it.

Keywords: government civil servants, admission of citizens to government service, competition, exam, oath, training, internships, certification, corruption, dismissal.

\author{
Новиков Андрей Борисович \\ Д.ю.н., профессор, Санкт-Петербургский \\ государственный экономический университет \\ docanovikov@mail.ru \\ Делегеоз Елена Геннадьевна \\ К.и.н., дочент, Санкт-Петербургский \\ государственный экономический университет \\ delegeozy@yandex.ru
}

Аннотация. Предметом исследования статьи является комплекс норм китайского и российского законодательства, касающихся правового регулирования отношений в сфере государственной гражданской службы. В статье проанализированы положения китайского законодательства, касающиеся поступления на государственную гражданскую службу, обучения государственных гражданских служащих и профилактики коррупции среди чиновников.

В результате проведенного анализа автор приходит к выводу, что Китай и Россия используют в целях противодействия коррупционным правонарушениям широкий арсенал мер юридической ответственности. В Китае применяется система «двойных рельсов» - подход, при котором ответственность лиц, подозреваемых в коррупционных преступлениях, наступает сначала по партийной линии, а затем по линии правоохранительных органов. В России серьезным дополнениям подверглись меры дисциплинарной ответственности в части введения нового вида наказания увольнение ввиду утраты доверия, которое может применяться в случаях несоблюдения антикоррупционных ограничений и запретов.

На основе проведенного сравнительно-правового анализа делается вывод о взаимном совершенствовании законодательств Китая и России путем внедрения в него лучших теоретических положений и практического опыта.

Ключевые слова: государственные гражданские служащие, прием граждан на государственную службу, конкурс, экзамен, присяга, обучение, стажировки, аттестация, коррупция, увольнение.

енная работа государственных гражданских служащих. Вот почему сравнительное изучение и конституционно-правовой анализ системы управления государственными служащими двух государств КНР и России так актуален в наши дни. Именно он позволяет выявить и позаимствовать друг у друга институциональные 
и практические преимущества, усовершенствовать систему управления государственной службой с учетом опыта внедрения его лучших достижений в свои государственные системы.

Согласно Конституции Китайской Народной Республики от 04.12.1982 г. (с изменениями от 11.03.2018 г.), В Китае установлен социалистический строй, особенностью которого является ведущая роль коммунистической партии. Принцип «партия управляет кадрами» лежит в основе системы государственной службы.

Кроме того, принципы организации государственной службы должны основываться на фундаментальных идеях марксизма, ленинизма, Мао Цзэдуна, Дэн Сяопина, «Тройного представительства» Цзян Цзэминя (партия представляет триаду интересов: народа, всех производительных сил, культуры), а также, Си Цзиньпина, провозгласившего ближайшую цель строительство «китайской мечты», которая на сегодняшний день получила статус официальной идеологии Китая.

Согласно ст. 2 Закона КНР «О государственной гражданской службе» государственный служащий - это персонал, осуществляющий публичные обязанности в соответствие с законом, состоящий в кадрах государственной администрации и получающий заработную плату и пособия за счет государственных финансов.

Согласно ст. 3 Конституции КНР принципом построения государственной гражданской службы является принцип демократического централизма, который осуществляется на национальном, провинциальном и уездном уровнях.

Органом, осуществляющим управление государственной гражданской службой в рамках всего Китая, является Государственная администрация гражданской службы КНР. Это положение закреплено в ст. 10 Конституции КНР.

При этом, департаменты каждого уровня государственной гражданской службы несут ответственность за организацию службы на местах.

Российская Федерация после 1991 г. отрицает социализм, а Конституция РФ от 12.12.1993 г. (с поправками) [1] в ст. 71 п. «Г» указывает только на федеральную государственную службу, не обозначая при этом границ между видами государственной службы, а в ст. 72 п. «б» ч. 1 определяет, что кадры правоохранительных органов (п. «л» ч. 1) отнесены к совместному ведению Российской Федерации и субъектов Российской Федерации.
Основным законом России о государственной службе является Федеральный закон от 27 мая 2003 г. № 58Ф3 «О системе государственной службы в Российской Федерации» [3].

Государственная служба РФ - это единая система, объединяющая три основных вида государственной службы: гражданскую, военную и правоохранительную $[2 ; 4 ; 6]$, под каждой из которых понимается профессиональная служебная деятельность граждан РФ по обеспечению полномочий Российской Федерации и органов государственной власти.

При этом, единство системы позволяет взаимодействовать между собой всем трем службам, допуская переход из одного вида службы в другие.

Действующий в КНР Закон «О государственной гражданской службе» (вступил в силу 01.01.2006 г.), (с изм. и доп. от 01.06.2019 г.) определяет порядок приема граждан на государственную службу. Прием осуществляется по результатам конкурса на основе открытого письменного экзамена и посредством интервью по вопросам организации государственной службы.

Примечательно два момента, которые, как думается, заслуживают особого внимания.

1. Проведением экзамена независимо от органа, куда поступает претендент, занимается Государственная администрация гражданской службы КНР или ее департаменты провинциального и уездного уровней. При этом, представители органа, открывшего вакансию к участию в проведении экзамена, не допускаются, что, на наш взгляд, повышает объективность результатов;

2. В КНР конкурс не проводится в два этапа, как В России. О проведении конкурса претендент на должность узнает из объявления, однако, его документы на предмет соответствия требованиям будут рассмотрены только после успешной сдачи экзамена. Требованиям к претенденту на государственную гражданскую службу следующие: гражданство КНР, возраст 18 лет, поддерживает Конституцию КНР, высокий уровень морали, необходимое здоровье и образование, не судим.

Если основу кадровой политики России составляет кадровый резерв, и при приеме на службу предпочтение отдается ему, то в Китае набор кадров осуществляется преимущественно из демобилизованных военнослужащих; из выпускников вузов, средних учебных заведений и профессиональных училищ; из выдвиженцев с предприятий и учреждений, с заводов и из деревень; из приглашенных лиц, прошедших определенную подготовку. При этом запрещено приглашать служащих 
на должности, связанные с государственной тайной. Кадрового резерва в Китае нет.

Согласно параграфу 3 ст. 27 гл. 1 «Основные принципы» Конституции КНР «все государственные служащие при вступлении в должность в соответствии с положениями законов публично приносят присягу на Конституции». Ничего подобного в России нет. Вновь принятые на работу госслужащие КНР должны выдержать годичный испытательный срок. В случае необходимости они могут работать по совместительству, но безвозмездно.

Вновь принятые на службу лица должны пройти обязательное обучение в зависимости от специфики занимаемой должности и освоить как основные навыки государственной службы в данном органе, так и специальные. Обучение проходят все лица, независимо от опыта предыдущей работы об этом говорит ст. 61 закона КНР «О государственной гражданской службе». В России обязательного обучения не проводится.

В ст. 66 Закона КНР «О государственной гражданской службе» также закреплено, что государственный гражданский служащий в целях выработки у него новых навыков может быть направлен на стажировку на государственное предприятие или в государственные органы, в том числе, находящиеся в другой провинции (уезде), на должность выше или ниже, чем та, которую он занимает, что, несомненно, способствует приобретению опыта, умению принимать самостоятельные решения и брать на себя принятие ответственных решений. Данные навыки дадут впоследствии возможность государству в эффективном использовании кадрового потенциала.

Как отмечается некоторыми авторами, «сегодня в приоритете не трудовой стаж кадрового работника, а его личные способности и заслуги. Уже остались в прошлом «пожизненные» руководящие должности государственных чиновников, что придает современный характер и жизнеспособность государственным административным органам и системе госслужбы в целом» [15].

При этом обучение государственных гражданских служащих в КНР осуществляется не только в обязательном порядке при принятии на службу, но и в рамках государственных программ и планов. Например, 13 декабря 2016 г. была принята Директива Канцелярии Госсовета КНP «Об учебных планах для государственных гражданских служащих в целях выполнения 13-го пятилетнего плана» [11].

Любое обучение в КНР должно заканчиваться аттестацией государственных гражданских служащих и проверкой их фактического обучения. Данными во- просами занимается Государственная администрация гражданской службы КНР соответствующего уровня.

Нельзя однозначно утверждать, что в России этого нет. Примером может служить учебные центры МВД по первоначальной подготовке, без прохождения которых невозможно дальнейшее прохождение службы [9], причем повышение квалификации и учебные сборы проводятся не реже одного раза в пять лет, в течение всей служебной деятельности сотрудников.

Конечно, этого нельзя сказать о гражданской и военной службах РФ. Однако, однозначно, можно утверждать, что и КНР, и Россия уделяют внимание повышению квалификации и обучению государственных гражданских служащих, что является позитивным моментом.

Что касается коррупции, с проявлениями которой неизбежно сталкиваются оба государства, то хочется отметить практику и России, и Китая. Законодательство КНР по данному вопросу состоит из трех основополагающих моментов:

1. «системы двойных рельсов», то есть подходе, при котором ответственность коррумпированного чиновника сначала идет по партийной линии, а затем по линии правоохранительных органов;

2. внедрение концепции «триады противодействия коррупции» (политика «трех не»): «не сметь брать взятку» (усиление наказания); «не мочь брать взятку» (контроль за доходами и расходами); «не хотеть брать взятку» (повышение сознательности).

Говоря о вопросе «усиления наказания» отметим, что п. 3 ст. 383 Уголовного кодекса КНР предусматривает смертную казнь за особо тяжкие коррупционные преступления. [11]

3. «Восьми правил по улучшению стиля работы и укреплению связей с народными массами», закрепленные решением политбюро ЦК КПК от 4 декабря 2012 года, которые по своему содержанию схожи с Российскими кодексами этики. Примером может выступить Типовой кодекс этики и служебного поведения государственных служащих Российской Федерации и муниципальных служащих [8].

Сегодня борьба с коррупцией является одним из приоритетов внутренней политики КНР. Основываясь на анализе Закона KHP «О государственной гражданской службе» и рассмотренных нормативных правовых актов, касающихся борьбы с коррупцией в КНР, сложно перечислить какие-либо значимые или более совершенные меры профилактического характера, аналогичные предусмотренным в национальном законодательстве Китая. 
В данном вопросе, думается, будет показательным опыт России, которая федеральным законом «О противодействии коррупции» ввела новый вид наказания увольнение за утрату доверия. Данный вид наказания применяется в случаях несоблюдения антикоррупционных ограничений и запретов, требований о предотвращении и урегулировании конфликта интересов и неисполнения, установленных в целях противодействия коррупции обязанностей.

Сведения о должностных лицах, в отношении которых применяется такая мера ответственности, как увольнение в связи с утратой доверия, включаются в реестр лиц, уволенных в связи с утратой доверия [7]. Российские СМИ уже назвали данный реестр онлайн-версией «доски позора».

Кроме того, Минтруд России на своем официальном сайте ведет Обзор типовых ситуаций конфликта интересов на государственной службе Российской Федерации и порядка их урегулирования. Обзор содержит не только описание различных ситуаций, в которых государственный служащий может оказаться, исполняя свои служебные обязанности, но и рекомендации по конкретным мерам предотвращения и урегулирования конфликта интересов [12].

Также обязательно размещение сведений о доходах, расходах, об имуществе государственных гражданских служащих и членов их семей в сети Интернет на официальных сайтах органов власти и отдельных категорий организаций [5]. К слову сказать, в КНР такого нет, сведения о доходах и об имуществе, представляемые государственными служащими и руководителями государственных предприятий, не публикуются и не размещаются в сети Интернет. Только организационные отделы партийных органов и прокуратура имеют доступ к этой информации для осуществления надзора со стороны органов прокуратуры.

Нельзя не отметить, что в России справки о доходах и расходах, об имуществе и обязательствах имущественного характера заполняются в полностью автоматическом режиме с помощью средств по специальному программному обеспечению - «Справки БК», который размещен на официальном сайте Президента РФ. Данная программа позволяет осуществлять проверку корректности вводимой информации [14].

Думается, что законодатель Российской Федерации на шаг впереди в решении данного вопроса.

Применительно к российской действительности была бы полезна практика применения порядка оплаты труда государственным гражданским служащим
КНР, заработная плата которых соответствует уровню развития экономики. Для этого проводится периодическое сравнение выплат, производимых государственным служащим, с уровнем заработка в коммерческих организациях. Если сравнивать порядок оплаты труда государственных гражданских служащих в КНР с порядком, закрепленным в Федеральном законе «О государственной гражданской службе Российской Федерации», то видно, что российский законодатель более четко урегулировал данный вопрос. Однако законодательством РФ не определено, что уровень оплаты труда государственного гражданского служащего должен формироваться с учетом уровня оплаты труда в коммерческих структурах. На сегодняшний день именно низкая заработная плата госслужащих в РФ определяет высокую текучесть кадров, как следствие этого непрофессионализм и невозможность решать поставленные государством задачи.

Познавательным с точки зрения практического применения является процесс увольнения с государственной гражданской службы в КНР. Китайское законодательство закрепляет два вида отставки государственных гражданских служащих: отставка по собственному желанию и отставка по инициативе работодателя.

Согласно ст. 80-81 Закона КНР «О государственной гражданской службе» государственный служащий, желающий уйти в отставку, обязан подать заявление, которое рассматривается компетентным органом в течение тридцати дней. В случае, если имеется одно из обстоятельств, а именно не достижение минимального срока службы; наличие незавершенного важного дела, касающегося публичных интересов; наличие в отношении государственного гражданского служащего незавершенного дисциплинарного расследования, проверки или уголовного расследования; наличие иных обстоятельств, установленных законом, подзаконными актами - добровольная отставка невозможна. Данные ограничения не применяются к руководящим сотрудникам, в случае их мотивированного заявления [13].

Думается, что данный порядок ограничивает право человека на труд, но рациональное зерно в этом есть. Бесспорно, в случае увольнения лица с государственной гражданской службы, не завершившего порученного дела, например, не сдав требуемую отчетность, как результат - негативные последствия для государственного органа.

В России увольнение по собственному желанию является самым популярным способом ухода от ответственности за неисполнение или ненадлежащее исполнение своих служебных обязанностей. Исходя из изложенного, данный опыт КНР заслуживает одобрения. 
Государственные гражданские служащие подлежат отставке по инициативе работодателя в следующих случаях: признание по результатам аттестации некомпетентным в течение двух лет подряд; отказ от принятия предложения о другой должности в связи с сокращением штата, слиянием, ликвидацией государственного органа; неисполнение должностных обязанностей и нарушение служебной дисциплины; отказ от прохождения обучения, если принято дисциплинарное взыскание в виде увольнения; отсутствие на рабочем месте более чем 15 дней подряд или 30 дней в течение года.

При этом государственные гражданские служащие не могут быть отправлены в отставку, в случае потери трудоспособности в результате исполнения своих должностных обязанностей; при прохождении лечения, или нахождения в отпуске по беременности и родам; перечень этот не исчерпывающий. Аналогичные положения есть и в законодательстве России.

Интересным для российского законодателя является то, что при выходе в отставку в отношении государственного служащего КНР может быть инициирована проверка, которая позволяет выявить наличие нарушений в деятельности служащего или незавершенность порученных им дел.

В рамках одной статьи нет возможности рассмотреть все аспекты государственной гражданской службы КНР и РФ. Обозначенные вопросы чрезвычайно важны и требуют глубокого изучения. Бесспорно одно: ряд положений Закона КНP «О государственной гражданской службе» заслуживает внимания и может быть использован для совершенствования отечественного законодательства.

Так, российскому законодателю следует рассмотреть возможность закрепления в законе обязанности проведения конкурсов на замещение вакантной должности государственной гражданской службы отдельным специализированным ведомством, а не тем органом, куда поступает претендент. Наличие независимого кадрового органа позволяет снизить вероятность проявления коррупционной составляющей при проведении конкурса со стороны руководителя органа, где имеется вакансия.

Следовательно, такой подход исключит проведение конкурсов с заранее определенным победителем и практику торговли должностями.

Заслуживает внимание опыт КНР, связанный с обучением государственных гражданских служащих. Прежде всего, следует рассмотреть возможность внедрения системы проведения обязательного обучения лиц, вновь поступивших на государственную службу, и осуществления контроля результатов такого обучения. Необходимо также в целях повышения профессиональных компетенций госслужащих рассмотреть перспективу проведения для них стажировок на государственных предприятиях, в государственных органах, в крупных коммерческих структурах. Такой подход позволит расширить профессиональные компетенции государственных гражданских служащих, сформировать новые и усовершенствовать практические навыки, научит самостоятельному принятию решений

Достаточно интересным, несмотря на свою неоднозначность, является подход китайского законодателя к увольнению государственных гражданских служащих. Возможно, стоит рассмотреть вопрос введения в закон нормы, позволяющей отказать государственному служащему в увольнении, в случае, не исполнения надлежащим образом возложенных на него обязанностей. Интересным представляется и осуществление последующих после увольнения проверок.

\section{ЛИТЕРАТУРА}

1. Конституция РФ с учетом поправок, внесенных Законом РФ о поправке к Конституции РФ от 14 марта 2020 г. № 1-ФКЗ, опубликован на «0фициальном интернет-портале правовой информации» (www.pravo.gov.ru) 4 июля 2020 г., в «Российской газете»» от 4 июля 2020 г. № 144.

2. Федеральный закон от 27 мая 1998 г. № 76-Ф3 «0 статусе военнослужащих»//Собрание законодательства РФ. 1998. № 22. Ст. 2331

3. Федеральный закон от 27 мая 2003 г. № 58-Ф3 «0 системе государственной службы в Российской Федерации»// Собрание законодательства РФ. 2003. № 22. Ст. 2063.

4. Федеральный закон от 27 июля 2004 г. № 79-Ф3 «0 государственной гражданской службе Российской Федерации»//Собрание законодательства РФ. 2004. № 31. Ст. 3215

5. Федеральный закон от 25 декабря 2008 г. № 273-Ф3 «0 противодействии коррупции»// Собрание законодательства Российской Федерации от 29 декабря 2008 г. № 52 (часть I) ст. 6228.

6. Федеральный закон от 30 ноября 2011 г. № 342-Ф3 «0 службе в органах внутренних дел Российской Федерации и внесении изменений в отдельные законодательные акты Российской Федерации»//Собрании законодательства Российской Федерации от 5 декабря 2011 г. № 49 (часть I) ст. 7020

7. Федеральный закон от 1 июля 2017 г. № 132-Ф3 «0 внесении изменений в отдельные законодательные акты Российской Федерации в части размещения в государственной информационной системе в области государственной службы сведений о применении взыскания в виде увольнения 
В связи с утратой доверия за совершение коррупционных правонарушений»//Собрание законодательства Российской Федерации от 3 июля 2017 г. № 27 ст. 3929.

8. Решение президиума Совета при Президенте РФ по противодействию коррупции от 23 декабря 2010 г. (протокол № 21).

9. Приказ МВД от 29.06.2009 № 490 «0б утверждении наставления по организации профессиональной подготовки сотрудников органов внутренних дел Российской Федерации»// СПС Гарант https://www.garant.ru/products/ipo/prime/doc/12068955/

10. Алексеенко А.П., Сонин В.В. Особенности законодательства КНР о государственной гражданской службе// Административное и муниципальное праB0. - 2017. - № 8. - С. 40-52.

11. Лю Хунянь. Стратегическая трансформация законодательства в сфере противодействия коррупции в Китае // Журнал зарубежного законодательства и сравнительного правоведения. - 2017. - № 5.- С. 116-121.

12. 0бзор типовых ситуаций конфликта интересов на государственной службе Российской Федерации и порядка их урегулирования https://mintrud.gov. ru/ministry/programms/anticorruption/9/1 (дата обращения 28.07.2021)

13. Опыт лучших практик государственной службы России и Китая: монография / отв. ред. Т.Я. Хабриева, Чжао Шимин; Институт законодательства и сравнительного правоведения при Правительстве Российской Федерации; Пудунская академия подготовки руководящих кадров Китая.- М.: ИД «Юриспруденция», 2020.- 396 с.

14. Справки БК (версия 2.5.0) и информационные материалы по заполнению справок о доходах, расходах, об имуществе и обязательствах имущественного характера http://www.kremlin.ru/structure/additional/12 (дата обращения 28.07.2021)

15. Хао Лун. Функционирование и развитие системы государственной службы в КНР на современном этапе. автореф. дис. канд. полит. наук. М., 2015.C. 27.

( Новиков Андрей Борисович ( docanovikov@mail.ru ), Делегеоз Елена Геннадьевна ( delegeozy@yandex.ru ).

Журнал «Современная наука: актуальные проблемы теории и практики»

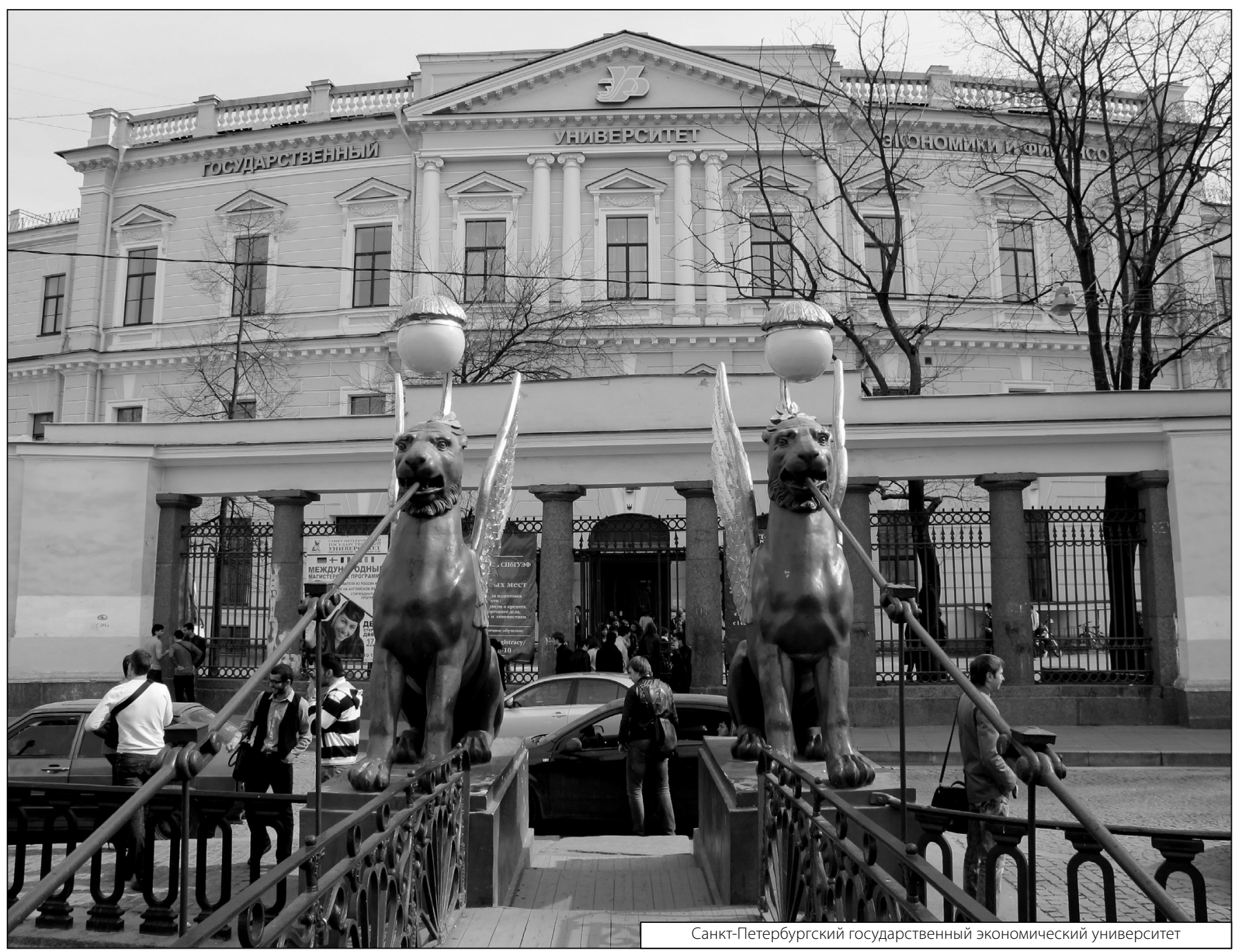

